\title{
Supporting Information \\ Insight into the Redox Reaction Heterogeneity within Secondary Particles of Nickel-Rich Layered Cathode Materials
}

Jiyang Li $i^{a}$, Jingxin Huang ${ }^{a}$, Hongyang Li $i^{b}$ Xiangbang Kong ${ }^{a}, X u e ~ L i{ }^{c}$, and Jinbao

Zhao $^{a, *}$

a State Key Laboratory of Physical Chemistry of Solid Surfaces, Collaborative Innovation Centre of Chemistry for Energy Materials, State-Province Joint Engineering Laboratory of Power Source Technology for New Energy Vehicle, Engineering Research Center of Electrochemical Technology, Ministry of Education, College of Chemistry and Chemical Engineering, Xiamen University, Xiamen, 361005, P.R. China.

b State Key Laboratory of Physical Chemistry of Solid Surfaces, College of Chemistry and Chemical Engineering, Xiamen University, Xiamen, 361005, P.R. China.

c National and Local Joint Engineering Laboratory for Lithium-ion Batteries and Materials Preparation Technology, Key Laboratory of Advanced Battery Materials of Yunnan Province, Faculty of Metallurgical and Energy Engineering, Kunming University of Science and Technology, Kunming, 650093, PR China.

Corresponding Authors

* E-mail: 438616074@qq.com (Xue Li). 
*E-mail: jbzhao@xmu.edu.cn (Jinbao Zhao). 

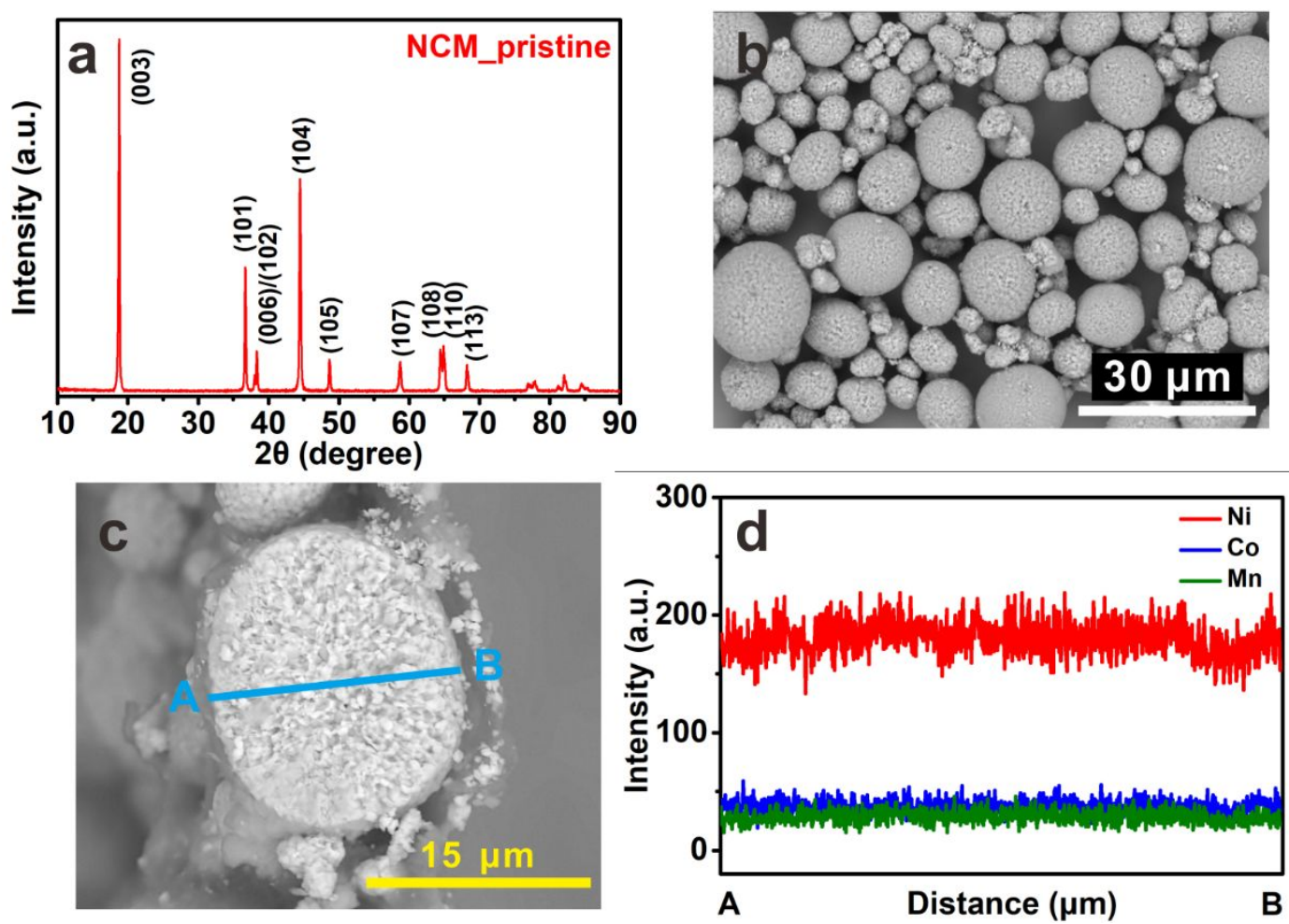

Figure S1. (a) The XRD pattern and (b) the SEM image of the pristine nickel-rich

NCM material. (c) The cross-sectional SEM image of the pristine secondary particle and the (d) EDS mapping of Ni, Co, Mn along the blue line. 


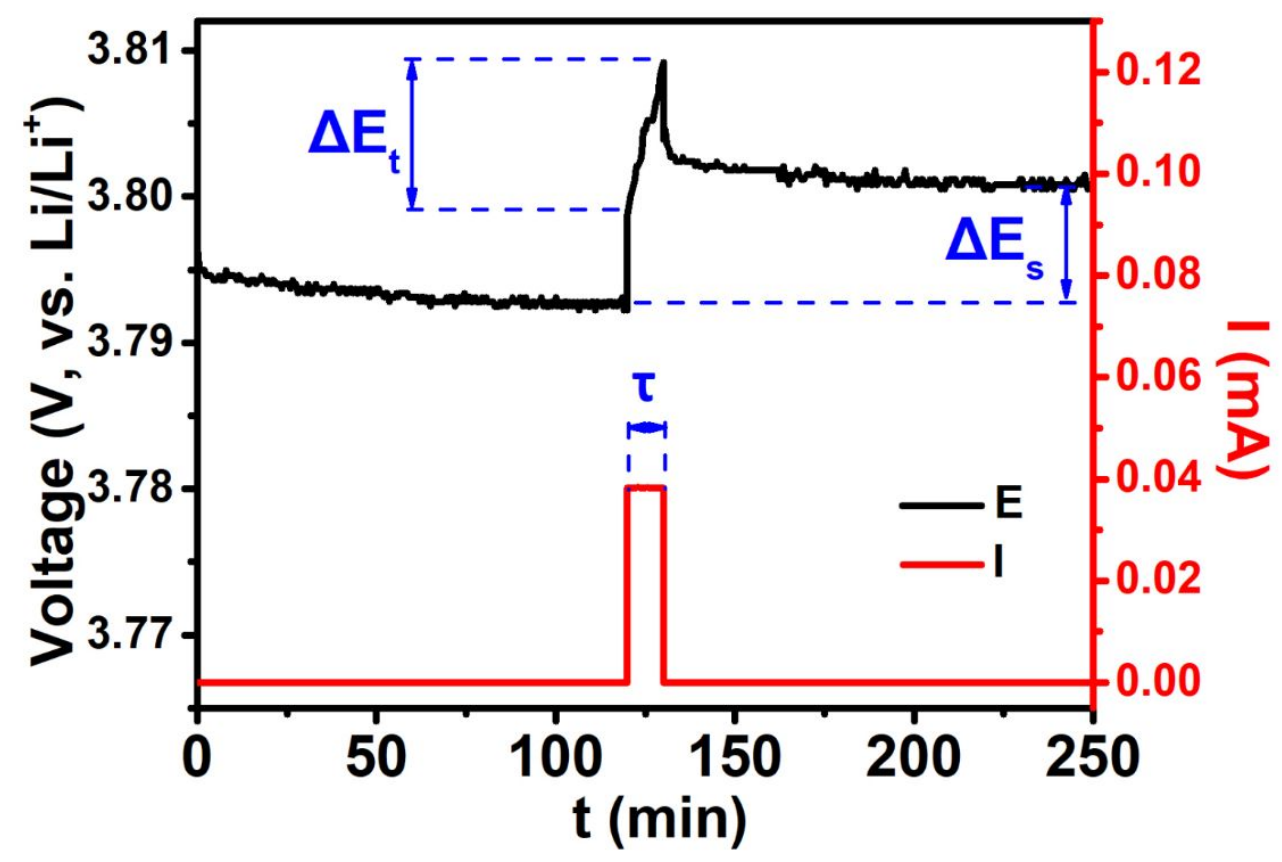

Figure S2. The voltage and current curves as a function of time for a relaxation-charge-relaxation step of the GITT dataset.

In the GITT measurement, the solid-phase $\mathrm{Li}^{+}$diffusion coefficient $\left(D_{L i}+\right)$ of the nickel-rich NCM material is calculated according to the following equation (1) ${ }^{1,2}$,

$$
D_{L i}{ }^{+}=\frac{4}{\pi \tau}\left(\frac{m V_{m}}{M S}\right)^{2}\left(\Delta E_{s} / \Delta E_{t}\right)^{2} \quad t \ll \frac{L^{2}}{D}
$$

Here, $\tau$ is the time of a single current pulse $(600 \mathrm{~s}) . \mathrm{m}$ is the mass of the active material. $\mathrm{V}_{\mathrm{m}}$ is the molar volume of the active material $\left(202.3 \times 10^{-7} \mathrm{~m}^{3} \cdot \mathrm{mol}^{-1}\right) . \mathrm{M}$ is the molar mass of the active material $\left(97.61 \mathrm{~g} \cdot \mathrm{mol}^{-1}\right) . \mathrm{S}$ is the surface area of the electrode $\left(1.131 \times 10^{-4} \mathrm{~m}^{2}\right) . \Delta \mathrm{E}_{\mathrm{s}}$ is the difference in the open circuit potential before and after the current pulse. $\Delta \mathrm{E}_{\mathrm{t}}$ is the change of the voltage during the current pulse, 
as shown in Figure S2. In Figure 1a, the average $D_{L^{+}}$during the charging/discharging cycle is approximately $1.42 \times 10^{-14} \mathrm{~m}^{2} \cdot \mathrm{s}^{-1}$.

The lithium ionic conductivity $\left(\sigma_{L i}{ }^{+}\right)$of the nickel-rich NCM material can be further calculated according to the Nernst-Einstein equation (2) ${ }^{3-5}$,

$$
\left.\sigma_{L i}=D_{L i}{ }^{n q^{2}} / k_{B} T\right)
$$

Here, $\mathrm{n}$ is the number of the charge carrier per unit volume $\left(2.98 \times 10^{28} \mathrm{~m}^{-3}\right) . \mathrm{q}$ is the charge of a single carrier $\left(1.6 \times 10^{-19} \mathrm{C}\right) . \mathrm{k}_{\mathrm{B}}$ is the Boltzmann constant $\left(1.38 \times 10^{-23}\right.$ $\left.\mathrm{J} \cdot \mathrm{K}^{-1}\right) . \mathrm{T}$ is the temperature in Kelvins $(298.15 \mathrm{~K})$. In Figure 1b, the average $\sigma_{L i}{ }^{+}$of the material is about $2.63 \times 10^{-2} \mathrm{mS} \cdot \mathrm{cm}^{-1}$ and much smaller than that of the electrolyte $\left(\sim 10.89 \mathrm{mS} \cdot \mathrm{cm}^{-1}\right)$. In fact, owing to the error caused by the actual $\mathrm{Li}^{+}$concentration gradient and the electrochemically active area in the electrode, the effective $D_{L^{+}}$is usually smaller than the apparent one measured by GITT.6, 7 So it can be concluded that the $\mathrm{Li}^{+}$diffusion in the solid phase of the nickel-rich NCM material is much slower than that in the liquid phase of electrolyte. 

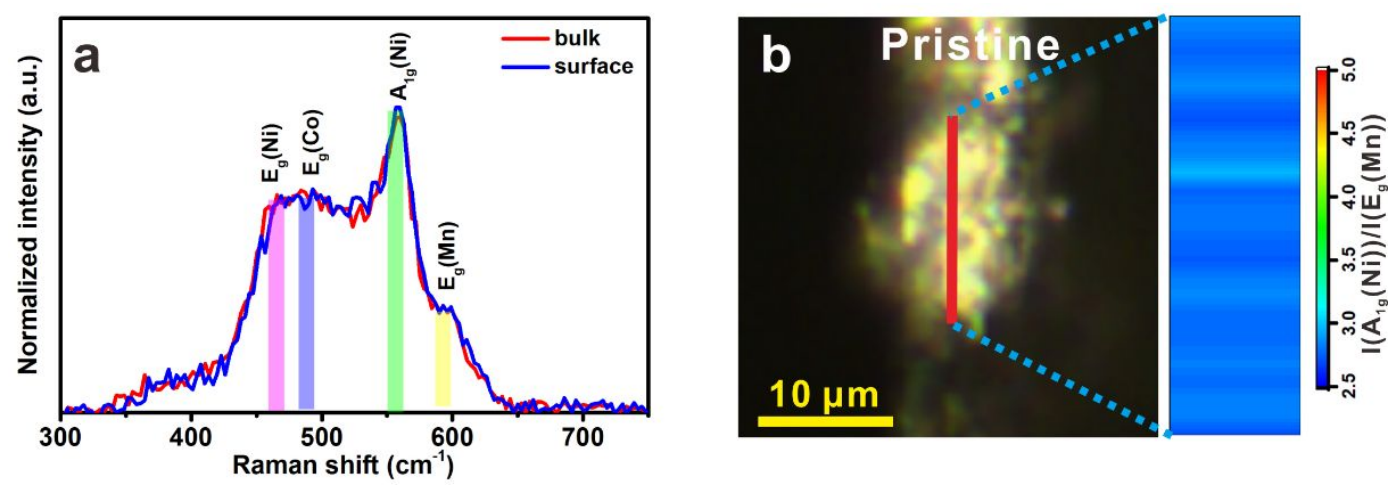

Figure S3. (a) The Raman spectra of the bulk and surface structure of the pristine nickel-rich NCM secondary particle. (b) The optical image of the cross-section of the pristine secondary particle and the contour map of the Raman spectral I $\left(\mathrm{A}_{1 \mathrm{~g}}(\mathrm{Ni})\right) / \mathrm{I}$ $\left(\mathrm{E}_{\mathrm{g}}(\mathrm{Mn})\right)$ value along the red line. 


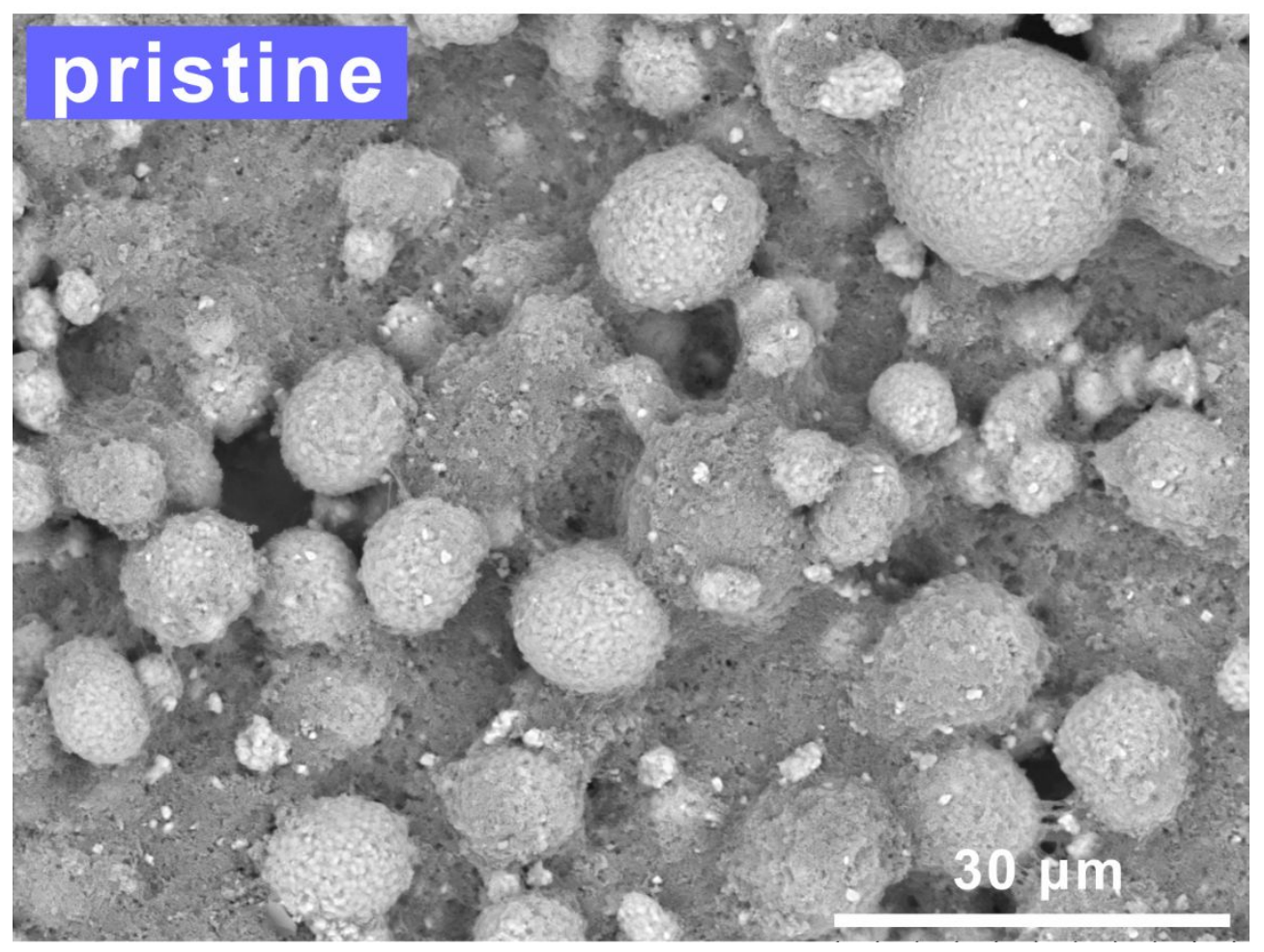

Figure S4. The SEM image of the pristine nickel-rich NCM electrode. 

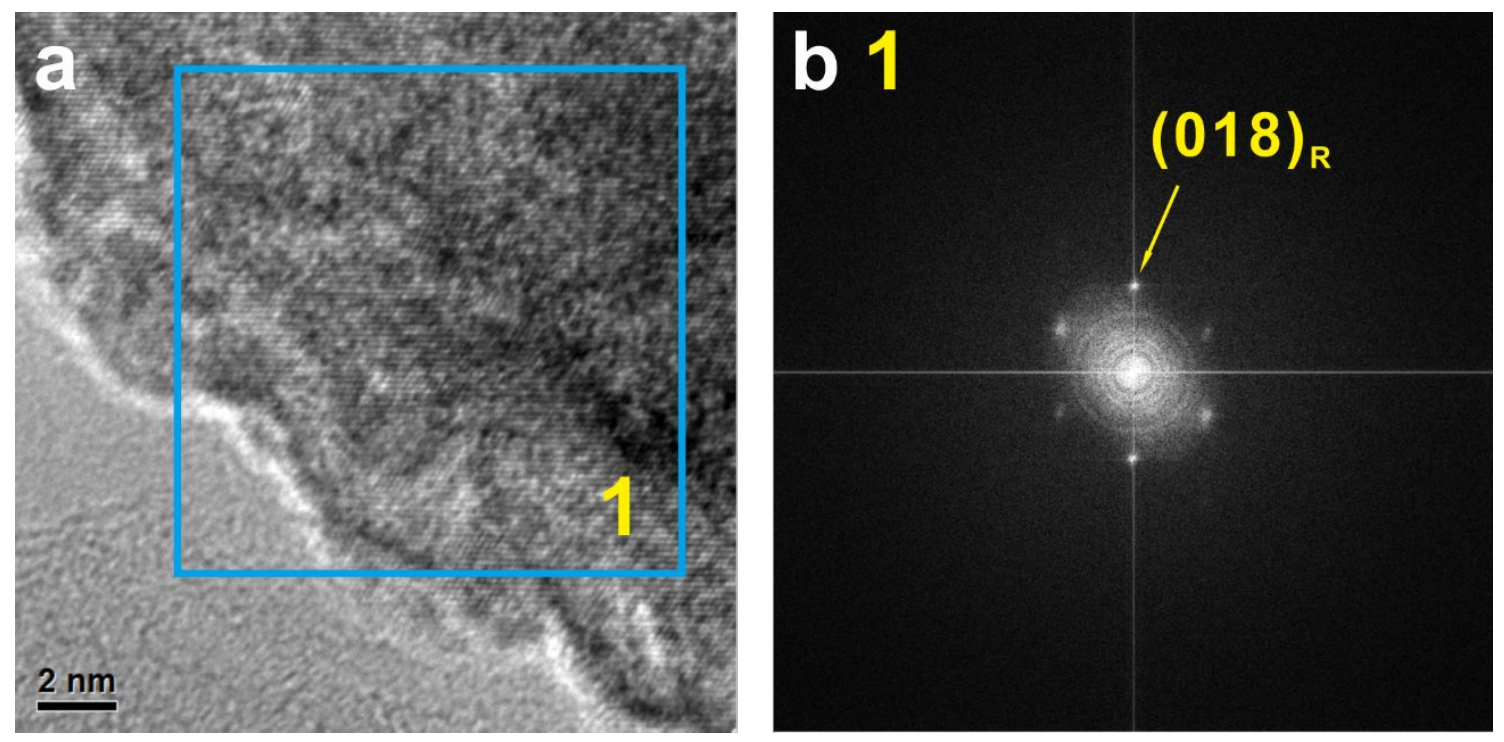

Figure S5. (a) The HR-TEM image of the pristine nickel-rich NCM material and (b) the FFT image of the selected region. 

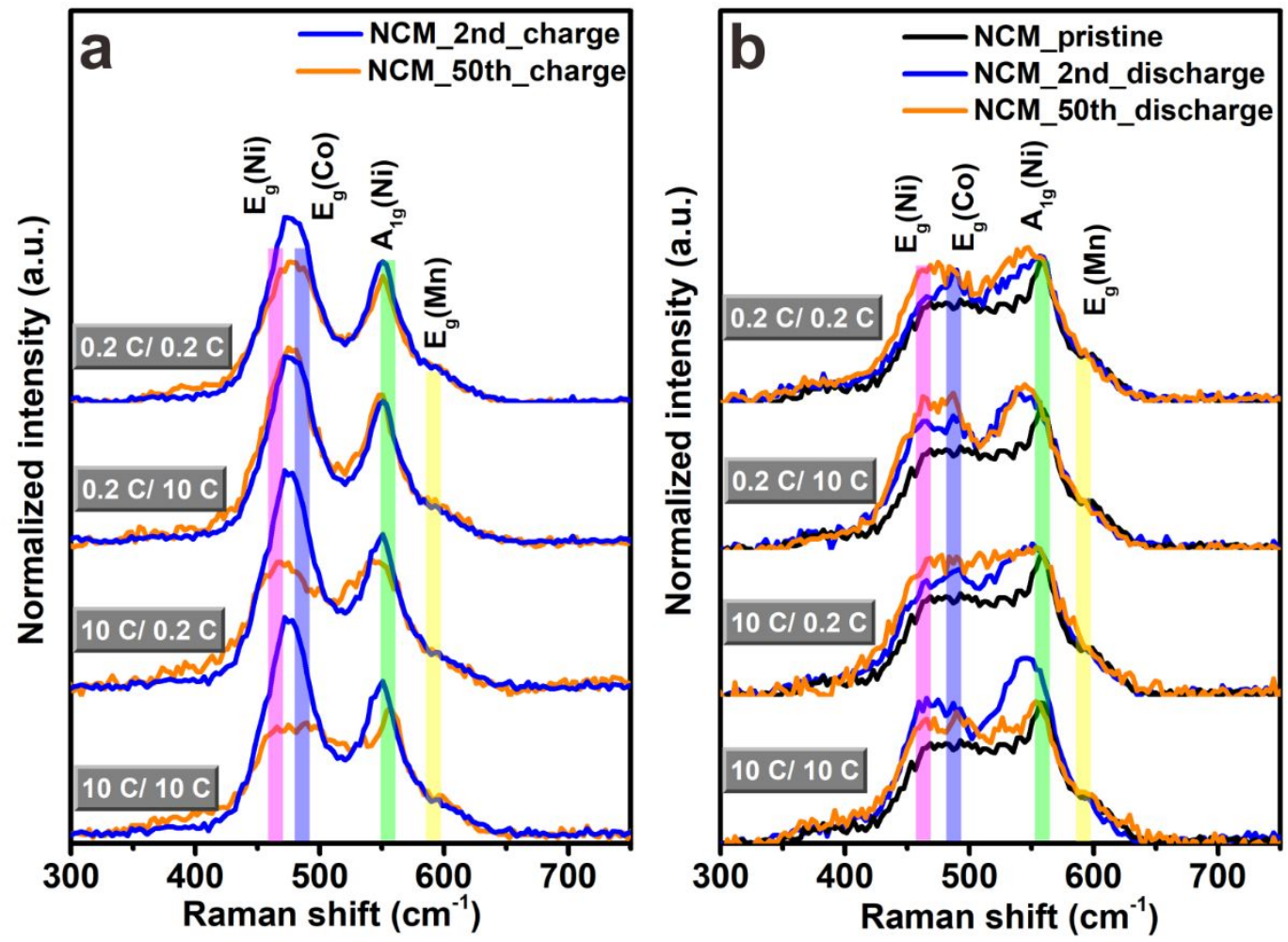

Figure S6. (a) The Raman spectra of the surface structure at the fully charged and (b) discharged state after 50 cycles compared with those at the initial cycle.

The changes in the redox reaction depth of the surface structure after 50 cycles at different charging/discharging rates are analyzed through Raman spectroscopy measurements. It is found that the increased electrode polarization would gradually reduce the depth of both the oxidation and reduction reactions of the material. Firstly, the $\mathrm{I}\left(\mathrm{A}_{1 \mathrm{~g}}(\mathrm{Ni})\right) / \mathrm{I}\left(\mathrm{E}_{\mathrm{g}}(\mathrm{Mn})\right)$ and $\mathrm{I}\left(\mathrm{E}_{\mathrm{g}}(\mathrm{Ni})\right) / \mathrm{I}\left(\mathrm{E}_{\mathrm{g}}(\mathrm{Mn})\right)$ values at the fully charged state (Figure S6a) decrease and the values at the fully discharged state (Figure S6b) increase obviously after cycling under almost all the conditions, which indicates a reduced redox reaction depth caused by the increased electrode polarization. Secondly, there exist two special samples. i) In Figure S6a, the $I\left(A_{1 g}(N i)\right) / I\left(E_{g}\right.$ 
$(\mathrm{Mn}))$ and $\mathrm{I}\left(\mathrm{E}_{\mathrm{g}}(\mathrm{Ni})\right) / \mathrm{I}\left(\mathrm{E}_{\mathrm{g}}(\mathrm{Mn})\right)$ values increase slightly after cycling under the " 0.2 $\mathrm{C} / 10 \mathrm{C}$ " condition. It is speculated that the surface structure would maintain the high oxidation depth during the subsequent low-rate charging process, due to the relatively small amount of Li intercalated during the high-rate discharging process (Figure 4e). ii) In Figure S6b, the values decrease after cycling under the " $10 \mathrm{C} / 10 \mathrm{C}$ " condition, which may be caused by the significantly decreased oxidation depth after cycling (Figure S6a) and the surface-concentrated reduction reaction during the high-rate discharging process jointly. In summary, the increased electrode polarization would gradually reduce the depth of the redox reactions of the nickel-rich NCM material, thus causing the capacity decay at different charging/discharging rates. Meanwhile, the continuously high oxidation depth during cycling at the " $0.2 \mathrm{C} / 10 \mathrm{C}$ " condition may aggravate the surface structural degradation, while the obviously decreased oxidation depth during cycling under the "10 C/ $0.2 \mathrm{C}$ " and "10 C/ $10 \mathrm{C}$ " conditions may delay the surface structural degradation effectively, which is consistent with the result in Figure 6. 


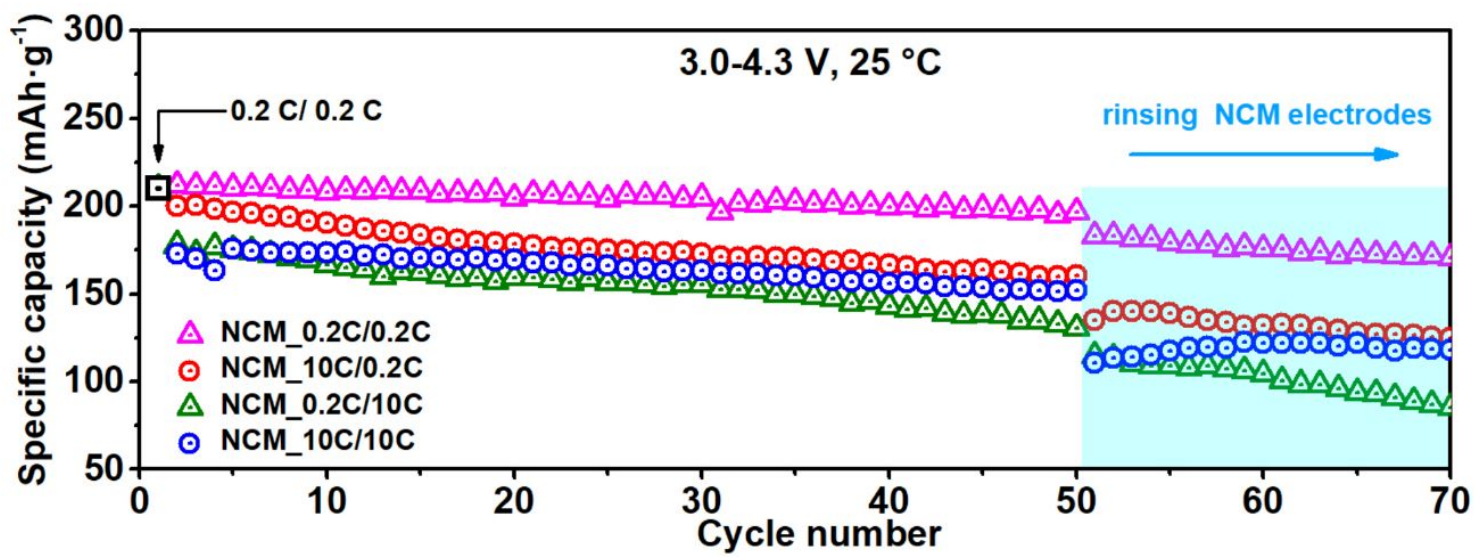

Figure S7. The cycle performance of the coin cells after rinsing the nickel-rich NCM electrodes and renewing the electrolyte. 

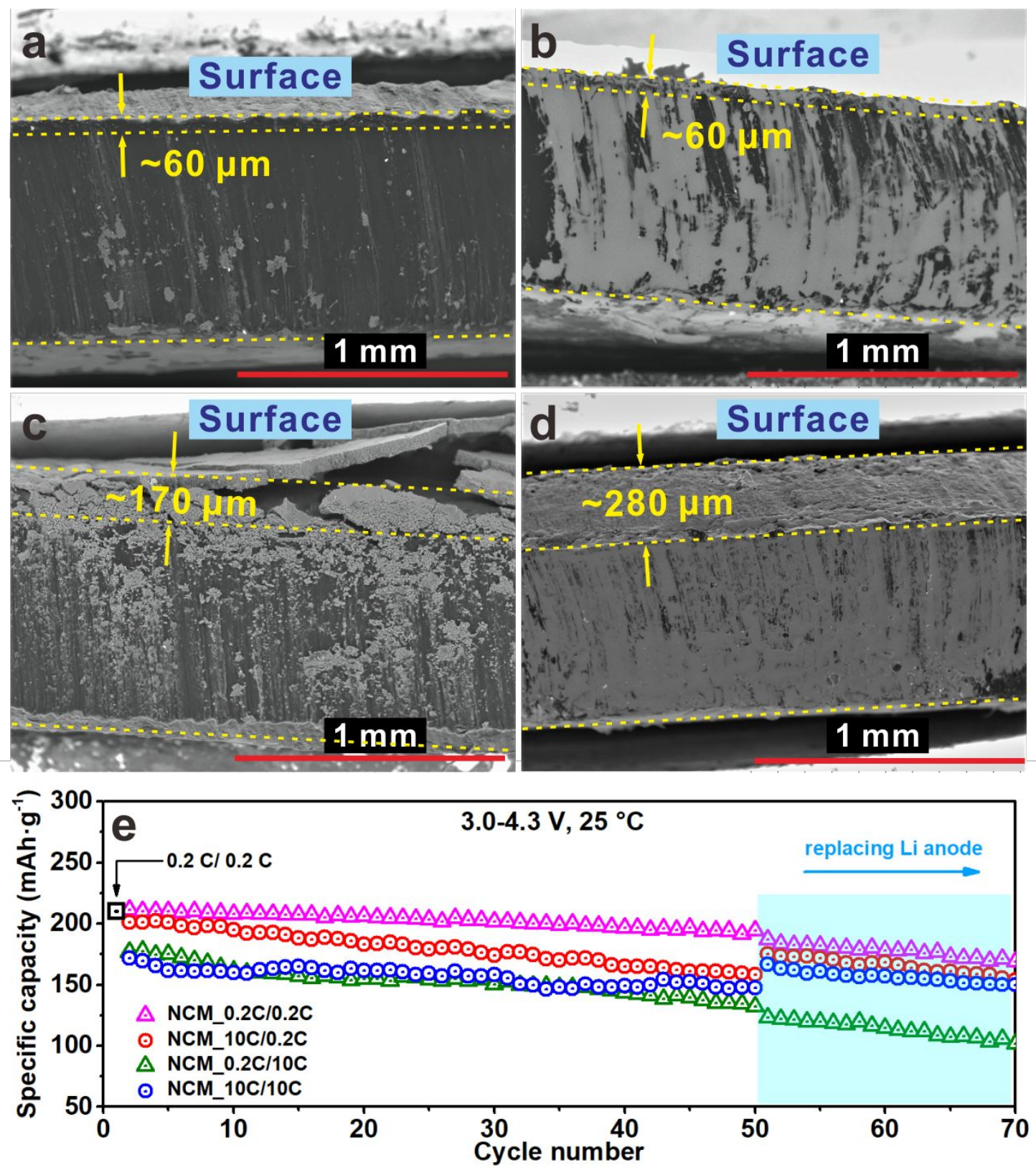

Figure S8. The SEM images of the cross-sections of the lithium metal anode after 50

cycles at different charging/discharging rates: (a) $0.2 \mathrm{C} / 0.2 \mathrm{C}$, (b) $0.2 \mathrm{C} / 10 \mathrm{C}$, (c) 10 $\mathrm{C} / 0.2 \mathrm{C}$ and (d) $10 \mathrm{C} / 10 \mathrm{C}$. (e) The cycling performance of coin cells after replacing the $\mathrm{Li}$ anode.

The correlation between the lithium metal anode and the kinetic degradation of $\mathrm{Li}^{+}$is verified through the SEM and electrochemical measurements. It is found that the $\mathrm{Li}^{+}$ 
kinetics would also degrade at the anode side, especially at the high-rate charging conditions. Firstly, Figure S8a-d show the cross-sections of the lithium metal anode after cycling at different charging/discharging rates. The thickness of the lithium metal anode used in this work is $\sim 1 \mathrm{~mm}$. In Figure S8a-b, a smooth surface layer with the thickness of $\sim 60 \mu \mathrm{m}$ appears on the lithium anode after cycling at the low-rate charging conditions, indicating a high utilization efficiency of the lithium anode. However, at the high-rate charging conditions (Figure S8c-d), there appears a rough and porous surface layer with the thickness of $\sim 170-280 \mu \mathrm{m}$, which implies a much lower utilization efficiency of the lithium metal. Secondly, the cycle performance of the nickel-rich NCM coin cells are tested after only replacing the Li metal anode. In Figure S8e, it is found that the capacities of the reassembled coin cells at the high-rate charging conditions can restore to a certain extent, rather than the low-rate charging conditions. It is speculated that the thick and porous surface layer formed at the high-rate charging conditions would tend to be separated from the bulk lithium anode to form the "dead lithium" and hinder the dissolution/deposition of $\mathrm{Li}^{+}$ at the anode side. Therefore, the anode-side kinetics of $\mathrm{Li}^{+}$would also deteriorate gradually during cycling, which is more obvious under the high-rate charging conditions than the low-rate charging conditions. 

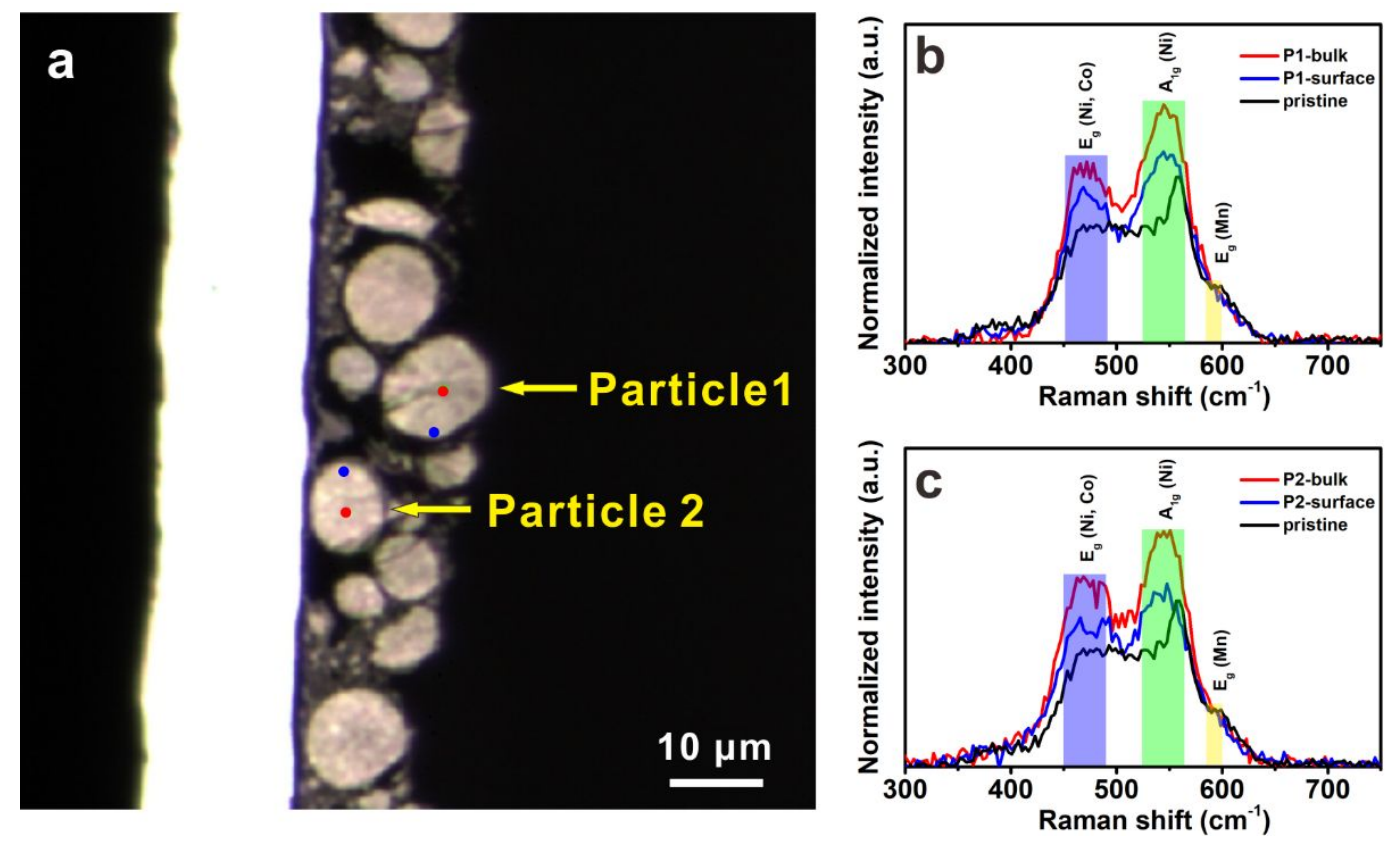

Figure S9. (a) The optical image of the cross-section of the nickel-rich NCM electrode after discharged at $10 \mathrm{C}$ and Raman spectral test sites of surface (the blue spot) and bulk (the red spot) structures for Particle 1 and Particle 2. (b-c) Raman spectra of surface and bulk structures for Particle 1 and Particle 2, respectively.

In order to eliminate the influence of the electrode-scale reaction heterogeneity on our work, especially under the high-rate condition, the nickel-rich NCM electrodes were prepared to be relatively loose and as thin as $\sim 15 \mu \mathrm{m}$, as shown in Figure S9a. Meanwhile, for different particles after the high-rate $(10 \mathrm{C})$ discharge, the surface values of $\mathrm{I}\left(\mathrm{A}_{1 \mathrm{~g}}(\mathrm{Ni})\right) / \mathrm{I}\left(\mathrm{E}_{\mathrm{g}}(\mathrm{Mn})\right)$ and $\mathrm{I}\left(\mathrm{E}_{\mathrm{g}}(\mathrm{Ni}, \mathrm{Co})\right) / \mathrm{I}\left(\mathrm{E}_{\mathrm{g}}(\mathrm{Mn})\right)$ are both much smaller than those of the bulk structures (Figure S9b-c). Therefore, in this work, the reaction between different particles at the electrode scale is believed to be relatively homogeneous, even at high-rate conditions, and the results obtained can help to understand the intrinsic rate dependency of the particle-scale reaction heterogeneity. 

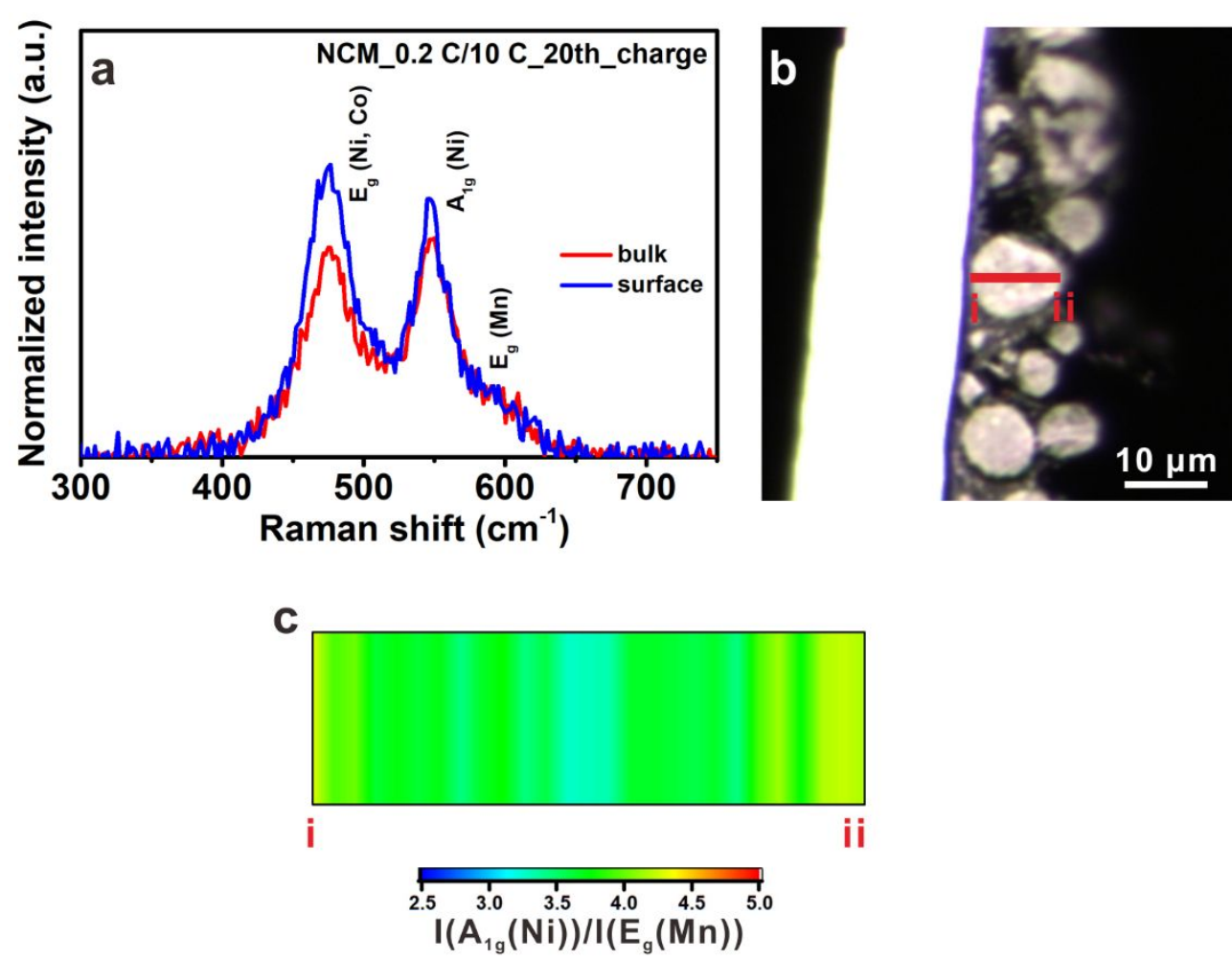

Figure S10. (a) Raman spectra of the surface and bulk structures and (b) the optical image of the cross-section of the fully charged materials after 20 cycles at the " 0.2 C/10 C" condition. (c) The contour map of the Raman spectral I $\left(\mathrm{A}_{1 \mathrm{~g}}(\mathrm{Ni})\right) / \mathrm{I}\left(\mathrm{E}_{\mathrm{g}}(\mathrm{Mn})\right)$ value along the red line from $\mathrm{i}$ to $\mathrm{ii}$. 

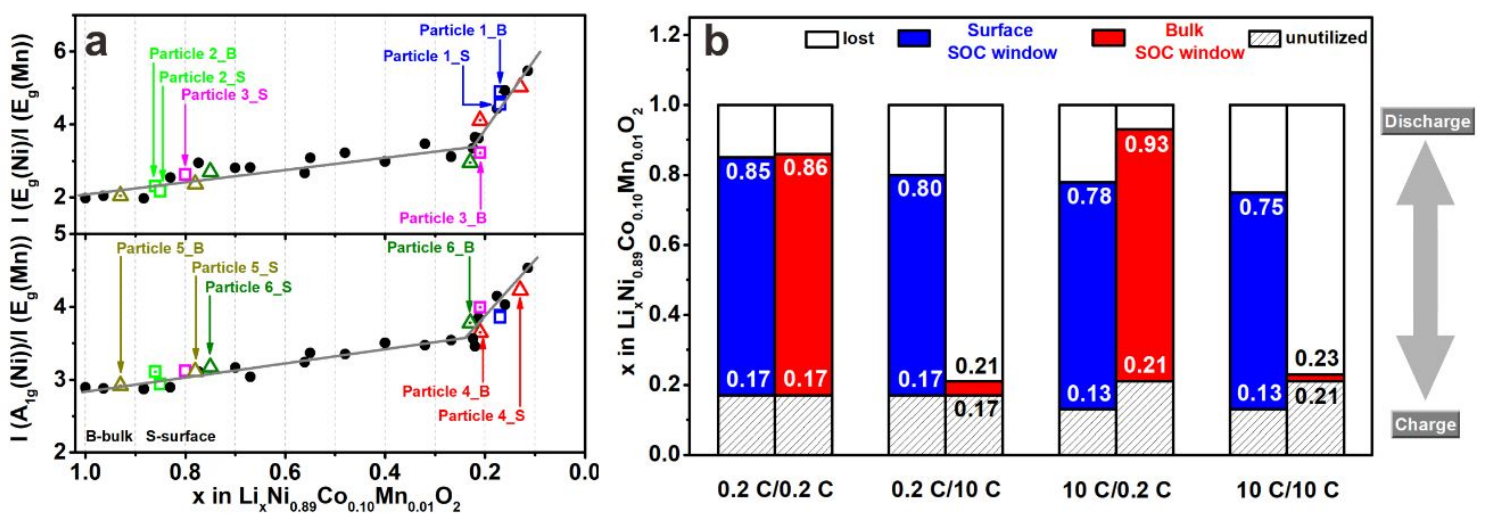

Figure S11. (a) The surface and bulk SOC values of different fully charged/discharged particles estimated from the correlation curves in Figure 2d: 0.2 C-charged Particle 1, 0.2 C-charged and 0.2 C-discharged Particle 2, 0.2 C-charged and 10 C-discharged Particle 3, 10 C-charged Particle 4, 10 C-charged and 0.2 C-discharged Particle 5, 10 C-charged and 10 C-discharged Particle 6. (b) Changes in SOC values of the surface and bulk structures during the charging/discharging process at different rate conditions.

\section{Exploration of the quantitative analysis for the reaction heterogeneity:}

As presented in Figure 2d, the values of I $\left(\mathrm{A}_{1 \mathrm{~g}}(\mathrm{Ni})\right) / \mathrm{I}\left(\mathrm{E}_{\mathrm{g}}(\mathrm{Mn})\right)$ and $\mathrm{I}\left(\mathrm{E}_{\mathrm{g}}(\mathrm{Ni})\right) / \mathrm{I}\left(\mathrm{E}_{\mathrm{g}}\right.$ (Mn)) change monotonously with the state-of-charge (SOC, $\mathrm{x}$ in $\mathrm{Li}_{\mathrm{x}} \mathrm{Ni}_{0.89} \mathrm{Co}_{0.10} \mathrm{Mn}_{0.01} \mathrm{O}_{2}$ ) of the nickel-rich NCM materials. Since this correlation curves is measured at the " $0.2 \mathrm{C} / 0.2 \mathrm{C}$ " condition, at which the redox reaction is proved to be homogeneous within the particle, the SOC values calculated through the specific charge/discharge capacity $\mathrm{Q}_{\text {charge }} / \mathrm{Q}_{\text {discharge }}\left[\mathrm{x}=1-\left(\mathrm{Q}_{\text {charge }}-\mathrm{Q}_{\text {discharge }}\right) / 273.16\right]$ can represent the real SOC of the local structure probed by Raman spectroscopy. As reported in the previous work, the Raman spectral characteristics can reflect the 
intrinsic SOC of NCM materials, because the vibrational characteristics of the metal-oxygen coordination structure are very sensitive to the $\mathrm{Li}$ amount and they correspond to each other. ${ }^{8-12}$ So it is possible to estimate the SOC values of the surface and bulk structures of different particles in Figure $\mathbf{3 b}$ according to the correlation curves in Figure 2d. Figure S11a and Table S3 exhibit the estimated process and the corresponding SOC values, respectively. Furthermore, the changes in SOC values of surface and bulk structures during the charging/discharging process at different rate conditions can be summarized in Figure S11b. Obviously, after the low-rate charge/discharge, almost no significant difference appears in SOC values between the particle surface and bulk. Noting that the individual difference at the fully discharged state under the "10 C/0.2 C" condition $(0.78 \mathrm{Li}$ and $0.93 \mathrm{Li})$ may be attributed to the over-delithiation of the surface structure after the high-rate charge. However, after the high-rate charge, the surface SOC value $(0.13 \mathrm{Li})$ is slightly smaller than the bulk one $(0.21 \mathrm{Li})$. After the high-rate discharge, the surface SOC values $(0.80 \mathrm{Li}$ and $0.75 \mathrm{Li})$ are significantly larger than the bulk ones $(0.21 \mathrm{Li}$ and $0.23 \mathrm{Li}$ ). Compared with the high-rate discharge, the relatively small gap between the surface and bulk SOC values after the high-rate charge may benefit from the constant-voltage charging step. Consequently, the reaction heterogeneity is possible to be analyzed quantitatively by Raman spectroscopy. 
Table S1. The initial specific capacity of the nickel-rich NCM material in the voltage region of 3.0-4.3 $\mathrm{V}$ at different charging/discharging rates.

\begin{tabular}{|c|c|c|c|c|}
\hline & \multicolumn{3}{|c|}{$\begin{array}{l}\text { Specific charge capacity } \\
\qquad\left(\mathrm{mAh} \cdot \mathrm{g}^{-1}\right)\end{array}$} & \multirow{2}{*}{$\begin{array}{c}\text { Specific discharge } \\
\text { capacity } \\
\left(\mathrm{mAh} \cdot \mathrm{g}^{-1}\right)\end{array}$} \\
\hline & Total & $\begin{array}{l}\text { Constant } \\
\text { current }\end{array}$ & $\begin{array}{c}\text { Constant } \\
\text { voltage }\end{array}$ & \\
\hline $0.2 \mathrm{C} / 0.2 \mathrm{C}$ & 214.3 & 212.1 & 2.2 & 209.6 \\
\hline $10 \mathrm{C} / 0.2 \mathrm{C}$ & 207.7 & 182.2 & 25.5 & 201.9 \\
\hline $0.2 \mathrm{C} / 10 \mathrm{C}$ & 215.7 & 212.9 & 2.8 & 175.2 \\
\hline $10 \mathrm{C} / 10 \mathrm{C}$ & 207.8 & 168.1 & 39.7 & 171.8 \\
\hline
\end{tabular}

Table S2. The cycle performance of the nickel-rich NCM material in the voltage region of 3.0-4.3 V at different charging/discharging current densities.

\begin{tabular}{|c|c|c|c|}
\hline & \multicolumn{2}{|c|}{$\begin{array}{l}\text { Specific discharge capacity } \\
\qquad\left(\mathrm{mAh} \cdot \mathrm{g}^{-1}\right)\end{array}$} & \multirow{2}{*}{$\begin{array}{c}\text { Capacity retention } \\
\text { (\%) }\end{array}$} \\
\hline & 2nd cycle & 100th cycle & \\
\hline $0.2 \mathrm{C} / 0.2 \mathrm{C}$ & 209.6 & 139.2 & 66.4 \\
\hline $10 \mathrm{C} / 0.2 \mathrm{C}$ & 201.9 & 115.7 & 57.3 \\
\hline $0.2 \mathrm{C} / 10 \mathrm{C}$ & 175.2 & 29.2 & 16.7 \\
\hline $10 \mathrm{C} / 10 \mathrm{C}$ & 171.8 & 113.1 & 65.8 \\
\hline
\end{tabular}

Table S3. The estimated SOC values of surface and bulk structures of different 
particles at different charging/discharging state in Figure 3b.

Surface SOC

Particle 1

(0.2 C-charged)

Particle 2

(0.2 C-charged and 0.2

C-discharged)

Particle 3

(0.2 C-charged and 10

0.80

0.21

C-discharged)

Particle 4

(10 C-charged)

Particle 5

(10 C-charged and 0.2

0.78

0.93

C-discharged)

\section{Particle 6}

(10 C-charged and 10

0.75

0.23

$\begin{array}{ll}0.13 & 0.21\end{array}$

0.17

0.86

0.17$$
.17
$$

0.85

C-discharged)

\section{Bulk SOC}

\begin{tabular}{ccc}
\hline & Surface SOC & Bulk SOC \\
\hline Particle 1 & 0.17 & 0.17 \\
$(0.2$ C-charged) & & \\
Particle 2 & 0.85 & 0.86 \\
$(0.2$ C-charged and 0.2 & & \\
C-discharged) & & 0.21 \\
Particle 3 & 0.80 & 0.21 \\
$(0.2$ C-charged and 10 & & 0.23 \\
C-discharged) & & \\
Particle 4 & 0.13 & \\
(10 C-charged) & & \\
Particle 5 & & \\
(10 C-charged and 0.2 & & \\
C-discharged) & & \\
Particle 6 & 0.78 & \\
(10 C-charged and 10 & & \\
C-discharged) & & \\
\hline
\end{tabular}




\section{References}

1. Hong, C.; Leng, Q.; Zhu, J.; Zheng, S.; He, H.; Li, Y.; Liu, R.; Wan,

J.; Yang, Y., Revealing the Correlation Between Structural Evolution and $\mathrm{Li}^{+}$ Diffusion Kinetics of Nickel-Rich Cathode Materials in Li-Ion Batteries. Journal of Materials Chemistry A 2020, 8 (17), 8540-8547.

2. Verma, A.; Smith, K.; Santhanagopalan, S.; Abraham, D.; Yao, K. P.; Mukherjee, P. P., Galvanostatic Intermittent Titration and Performance Based Analysis of LiNi0.5Co0.2Mn0.3O2 Cathode. Journal of The Electrochemical Society 2017, 164 (13), A3380-A3392.

3. Kunze, M.; Karatas, Y.; Wiemhöfer, H.-D.; Schönhoff, M., Correlations of Ion Motion and Chain Motion in Salt-in-Polysiloxane-g-Oligoether Electrolytes. Macromolecules 2012, 45 (20), 8328-8335.

4. Petrowsky, M.; Fleshman, A.; Bopege, D. N.; Frech, R., Ion Transport with Charge-Protected and Non-Charge-Protected Cations Using the Compensated Arrhenius Formalism. Part 2. Relationship Between Ionic Conductivity and Diffusion. The Journal of Physical Chemistry B 2012, 116 (31), 9303-9309.

5. Joo, J. H.; Bae, Y. C., Ionic Conductivities of Solid Polymer Electrolyte/Salt Systems: Group-Contribution Method. Journal of Power Sources 2006, 157 (1), $448-456$.

6. Dees, D. W.; Kawauchi, S.; Abraham, D. P.; Prakash, J., Analysis of the Galvanostatic Intermittent Titration Technique (GITT) as Applied to a Lithium-Ion Porous Electrode. Journal of Power Sources 2009, 189 (1), 263-268. 
7. Gao, H.; Wu, Q.; Hu, Y.; Zheng, J. P.; Amine, K.; Chen, Z., Revealing the Rate-Limiting Li-Ion Diffusion Pathway in Ultrathick Electrodes for Li-Ion Batteries. The Journal of Physical Chemistry Letters 2018, 9 (17), 5100-5104.

8. Lanz, P.; Villevieille, C.; Novák, P., Ex Situ and In Situ Raman Microscopic Investigation of the Differences between Stoichiometric LiMO2 and High-Energy xLi2MnO3 (1-x)LiMO2 (M = Ni, Co, Mn). Electrochimica Acta 2014, 130, 206-212.

9. Fang, S.; Yan, M.; Hamers, R. J., Cell Design and Image Analysis for In-Situ Raman Mapping of Inhomogeneous State-of-Charge Profiles in Lithium-Ion Batteries. Journal of Power Sources 2017, 352, 18-25.

10. Flores, E.; Vonrüti, N.; Novák, P.; Aschauer, U.; Berg, E. J., Elucidation of LixNi0.8Co0.15A10.05O2 Redox Chemistry by Operando Raman Spectroscopy. Chemistry of Materials 2018, 30 (14), 4694-4703.

11. Flores, E.; Novák, P.; Aschauer, U.; Berg, E. J., Cation Ordering and Redox Chemistry of Layered Ni-Rich LixNi1-2yCoyMnyO2: An Operando Raman Spectroscopy Study. Chemistry of Materials 2019, 32 (1), 186-194.

12. Li, J.; Huang, J.; Kong, X.; Zeng, J.; Zhao, J., The Apparent Capacity Decay by Kinetic Degradation of LiNi0.5Co0.2Mn0.3O2 during Cycling under the High Upper-Limit Charging Potential. Journal of Power Sources 2021, 496, 229856. 